\title{
Risk factors for coronary heart disease in patients with spinal cord injury in Turkey
}

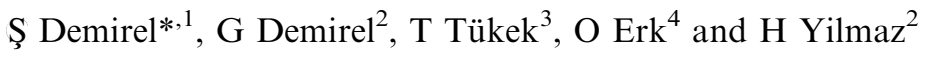 \\ ${ }^{1}$ Cardiovascular Diseases Research Centre, Istanbul University Medical Faculty, Istanbul, Turkey; ${ }^{2}$ Istanbul Physical \\ Therapy and Rehabilitation Centre, Istanbul, Turkey; ${ }^{3}$ Internal Medicine, Istanbul University Medical Faculty, \\ Istanbul, Turkey; ${ }^{4}$ Department of Emergency Medicine, Internal Medicine, Istanbul University Medical Faculty, \\ Istanbul, Turkey
}

\begin{abstract}
Objective: To compare the standard risk factors for coronary heart disease (CHD), defined in National Cholesterol Education Program II (NCEP II) of Turkish spinal cord injury (SCI) patients with healthy controls, discuss the results according to the findings in Turkish population, and SCI patients in the literature.

Design: We assessed 52 age and sex matched healthy control subjects, and 69 SCI patients (16 females, 53 males with the mean age of $33.9 \pm 11.37$ years) with time since injury of $12.8 \pm 13.45$ months. The study consisted of 45 paraplegics, and 24 tetraplegics with $54 \%$ incomplete, and $46 \%$ complete injury.

Results: Risk factors for CHD according to NCEP II were; age and sex in $16 \%$, positive family history in $0 \%$, cigarette smoking in $54 \%$, hypertension (HT) in $0 \%$, high total cholesterol (TC) in 32\%, high low-density lipoprotein cholesterol (LDL) in $41 \%$, low highdensity lipoprotein cholesterol (HDL) in $52 \%$, and diabetes mellitus (DM) in $7 \%$ of our SCI patients, respectively. Compared to controls DM, high TC, LDL, and low HDL were statistically more frequent in SCI patients. We found a negative correlation between serum HDL and time since injury. TC $(186 \pm 32$ vs $205 \pm 36 ; P=0.025)$, TC/HDL $(5.34 \pm 1.17$ vs $6.26 \pm 1.5 ; P=0.005)$, and LDL/HDL $(3.57 \pm 0.9$ vs $4.16 \pm 1.3 ; P=0.027)$ were significantly increased in patients with time since injury of more than 1 year, while HDL levels $(35.8 \pm 6.36$ vs $33.86 \pm 6.47 ; P=0.213)$ decreased without reaching statistical significance. The lipid profiles did not show any correlation with the neurological level, and completeness of lesions.

Conclusions: SCI confers additional CHD risk over that present inherently in the parent population due to enforced sedentary lifestyle and this increases with time since injury.

The preliminary study consisting of 26 patients was accepted for poster presentation in Copenhagen, Denmark (18-20 June 1999) at the 38th Annual Scientific Meeting of IMSOP in association with the Nordic Medical Society of Paraplegia.
\end{abstract}

Spinal Cord (2001) 39, 134-138

Keywords: spinal cord injury; risk factors for coronary heart disease; Turkish population; Turkish spinal cord injured patients

\section{Introduction}

Previous studies have reported an adverse coronary heart disease (CHD) risk profile in patients with spinal cord injury (SCI). ${ }^{1-3}$ As SCI patients survive longer because of the implementation of modern therapeutic modalities on life threatening complications such as urinary tract infections and pressure sores, the importance of the management of coronary risk factors is likely to increase. Depressed values of high density lipoprotein cholesterol (HDL) have been reported repeatedly in comparison with able bodied subjects $^{4-8}$ which may be due to increased proportion

*Correspondence: Ş Demirel, Akıncı Bayırı Sokak, Dinçkurt Ap. 22A, D 8, 80290 Mecidiyeköy, Istanbul, Turkey of adipose tissue,$^{8,9}$ ethnicity, ${ }^{10}$ extremely low levels of physical activity, ${ }^{4,5,11}$ time since injury, ${ }^{4,12,13}$ and level and completeness of lesion. ${ }^{10}$ Abnormalities of carbohydrate metabolism, insulin resistance, and hyperinsulinemia have also been described in subjects with SCI. ${ }^{14}$

The Turkish population has inherent risk factors arising from their genetic make-up aside from the standard risk factors defined in National Cholesterol Education Program II (NCEP II). ${ }^{15}$ The purpose of the study was to compare the standard coronary risk factors of the SCI patients with a healthy control group, and discuss the results according to the findings in Turkish population, and SCI patients in the literature. 


\section{Material and methods}

We assessed 69 SCI patients during their rehabilitation period in our centre. The time since injury was $12.8 \pm 13.45$ months (range 2-84 months). Sixteen $(23 \%)$ females and $53(77 \%)$ males were evaluated. The mean age of the patients was $33.9 \pm 11.37$ years (range $10-70$ years). The mean age of males was $33.7 \pm 12.1$, of females $34.6 \pm 8.6$ years, respectively. Written informed consent was obtained from all patients. The determination of the level of SCI was based on a comprehensive standardized manually performed physical examination. ${ }^{16}$ The study consisted of 45 paraplegics $(67 \%)$ and 24 tetraplegics $(33 \%)$. ASIA impairment scale indicated 37 incomplete $(54 \%)$, and 32 complete $(46 \%)$ injury. In paraplegics 23 complete $(52 \%)$, and 22 incomplete $(48 \%)$ injury were investigated. In tetraplegics there were $15(62 \%)$ incomplete and nine $(38 \%)$ complete injury. Traffic accident $(58 \%)$ was the most common cause. The other causes were: driving two (3\%), infection four $(6 \%)$, trauma two $(3 \%)$, vascular two $(3 \%)$, weapon seven $(10 \%)$, and fall $12(17 \%)$.

Our control group which consisted of 52 subjects (14 females $(27 \%), 38$ males $(73 \%)$, mean age $35.5 \pm 7.72$ years) was selected from young medical staff during their annual check up.

Body weight was measured on a balance beam scale designed to accommodate wheelchairs. Body length was measured to the nearest centimeter in a supine position using a plastic measuring tape. Measurements for the abdominal circumference (AC) were made at umbilicus after a normal expiration with subjects supine. Body mass index (BMI) was calculated as the weight in $\mathrm{kg}$ divided by the squared height in meters, and $>27 \mathrm{~kg} / \mathrm{m}^{2}$ is a contributing risk factor. ${ }^{17}$

Conicity index (CI), an index of abdominal adiposity was measured as described by Valdez et $a l .{ }^{18} \mathrm{CI}$ is equal the abdominal circumference in $\mathrm{m} / 0.109$ square-root weight/height in $\mathrm{kg}$ and $\mathrm{m}$, respectively.

A diastolic blood pressure above $90 \mathrm{mmHg}$ and a sistolic blood pressure above $140 \mathrm{mmHg}$ or being on antihypertensive treatment were considered as diagnostic for hypertension (HT). ${ }^{19}$ Diabetes mellitus (DM) and impaired fasting glucose (IFG) were defined according to the report of the Expert Committee on the Diagnosis and Classification of Diabetes Mellitus. ${ }^{20}$ A questionnaire was used to assess alcohol consumption (number of glasses per week), smoking behavior (number of cigarettes per day) and family history of CHD. Blood samples were obtained after an overnight fast. Total cholesterol (TC) and triglycerid (TG) concentrations were measured using enzymatic tests on the Olympus Au560 automated analyzer (Japan). HDL was determined after selective precipitation of the very low density lipoprotein-cholesterol (VLDL) and low density lipoprotein-cholesterol (LDL). LDL in $\mathrm{mg} / \mathrm{dl}$ was calculated according to the Friedewald equation as follows: $\mathrm{LDL}=\mathrm{TC}-(\mathrm{HDL}+\mathrm{TG} / 5) .{ }^{21}$ Serum uric acid
(SUA) and plasma glucose were measured by automated blood analyzer.

The results are reported as mean \pm standard deviation. The limits of statistical significance was $P<0.05$. Correlation between two groups were carried out with Pearson bivariate correlation tests. Numerical variables were compared with Student's $t$-test. Non numerical values were compared with $\chi^{2}$ test. In $2 \times 2$ contigency tables Yates correction was done. When assumptions were violated in $2 \times 2$ tables Fischer's exact test was used. The statistical analysis was done by using Statistical Package for Social Sciences (SPSS) for Windows 10.0.

\section{Results}

Demographic parameters of our SCI patients and controls are shown in Table 1. Means and standard deviations for biochemical and demographic parameters as well as the proportion of subjects falling outside the 'normal range' are shown in Table 1 and 2. Impaired fasting glucose, DM, hyperuricemia, high TC, LDL, low HDL, high TC/HDL, LDL/HDL ratios were statistically more common in the SCI group, while positive family history was statistically more common in the control group (Table 2). Age, sex, HT, obesity, high TG, and smoking were not statistically different between the groups. Time since injury was correlated directly with TC/HDL and LDL/HDL ratios, inversely with HDL $(P<0.01, \quad \mathrm{r}=0.36$; $P<0.05, \quad \mathrm{r}=0.27 ; \quad P<0.05, \mathrm{r}=-0.26$, respectively). TC $\quad(186 \pm 32$ vs $205 \pm 36 ; \quad P=0.025), \quad$ TC/HDL $(5.34 \pm 1.17$ vs $6.26 \pm 1.5 ; P=0.005)$, and LDL/HDL $(3.57 \pm 0.9$ vs $4.16 \pm 1.3 ; \quad P=0.027)$ were increased significantly with time since injury more than one year while HDL levels $(35.8 \pm 6.36$ vs $33.86 \pm 6.47$; $P=0.213$ ) decreased without reaching statistical significance. HDL showed inverse correlations with time since injury, TG, TC/HDL, and $\mathrm{LDL} / \mathrm{HDL}$ ratios $(P<0.05, \mathrm{r}=-0.24 ; \quad P<0.001 ; \mathrm{r}=-0.71 ; P<0.001$, $\mathrm{r}=-0.57$, respectively). The lipid profiles did not show any correlation with the neurological level, and completeness of lesions. There was no statistically significant difference for CHD risk factors in tetraplegics and paraplegics or for complete and incomplete lesions. SUA levels were directly correlated with TC $(P<0.01 ; \mathrm{r}=0.36)$, TG $(P<0.001 ; \mathrm{r}=0.46)$, and TC/ HDL ratio $(P=0.01 ; \mathrm{r}=0.30)$. No patient or control had a history of alcohol consumption, and drug use affecting CHD risk factors.

\section{Discussion}

We found, that the SCI group had more risk factors for CHD compared to the age and sex matched control group. Obesity, high $\mathrm{TG}$, and smoking were more common in the SCI group without reaching statistical significance. The adverse risk profile of increased TC and ratios TC/HDL, LDL/HDL were more common with time since injury greater than 12 months. 
Table 1 Demographic parameters of SCI patients and controls

\begin{tabular}{|c|c|c|c|}
\hline & Controls $(\mathrm{n}=52)$ & SCI patients $(\mathrm{n}=69)$ & $\mathrm{P}$ value \\
\hline Age (years) & $35.5 \pm 8$ & $34 \pm 11$ & N.S \\
\hline \multicolumn{4}{|l|}{ Sex } \\
\hline Males & $38(73 \%)$ & $53(77 \%)$ & \multirow[t]{2}{*}{ N.S. } \\
\hline Females & $14(27 \%)$ & $16(23 \%)$ & \\
\hline Height (m) & $1.68 \pm 8.7$ & $1.7 \pm 8.2$ & N.S. \\
\hline Weight $(\mathrm{kg})$ & $70.2 \pm 9.9$ & $73.6 \pm 12$ & N.S. \\
\hline Abdominal circumference $(\mathrm{cm})$ & $85.7 \pm 11$ & $84.8 \pm 10$ & N.S. \\
\hline Conicity index & $1.21 \pm 0.15$ & $1.18 \pm 0.09$ & N.S. \\
\hline $\operatorname{BMI}\left(\mathrm{kg} / \mathrm{m}^{2}\right)$ & $24.97 \pm 3.3$ & $25.5 \pm 4$ & N.S. \\
\hline Duration of SCI (months) & & $12.8 \pm 14$ & N.S. \\
\hline \multicolumn{4}{|l|}{ Biochemistry } \\
\hline Glucose (mg/dl) & $82 \pm 9$ & $92 \pm 18$ & $\mathrm{P}<0.001$ \\
\hline Uric acid $(\mathrm{mg} / \mathrm{dl})$ & $3.8 \pm 1$ & $5.8 \pm 2$ & $\mathrm{P}<0.001$ \\
\hline Total cholesterol (mg/dl) & $166 \pm 22$ & $194 \pm 35$ & $\mathrm{P}<0.001$ \\
\hline Triglycerides $(\mathrm{mg} / \mathrm{dl})$ & $130 \pm 50$ & $138 \pm 63$ & N.S. \\
\hline HDL cholesterol (mg/dl) & $42 \pm 8$ & $35 \pm 7$ & $\mathrm{P}<0.001$ \\
\hline LDL cholesterol (mg/dl) & $98 \pm 16$ & $130 \pm 32$ & $\mathrm{P}<0.001$ \\
\hline VLDL cholesterol (mg/dl) & $26 \pm 10$ & $28 \pm 13$ & N.S. \\
\hline Total cholesterol/HDL-cholesterol & $4.1 \pm 0.8$ & $5.73 \pm 1.39$ & $\mathrm{P}<0.001$ \\
\hline LDL-cholesterol/HDL-cholesterol & $2.45 \pm 1.11$ & $3.82 \pm 1.11$ & $\mathrm{P}<0.001$ \\
\hline
\end{tabular}

Table 2 Cardiovascular risk and contributing factors

\begin{tabular}{|c|c|c|c|}
\hline & Controls $(\mathrm{n}=52)$ & SCI patients $(\mathrm{n}=69)$ & $\mathrm{P}$ value \\
\hline Age $>45$ years for males & $6(11 \%)$ & $11(16 \%)$ & 0.54 \\
\hline $\begin{array}{l}\text { Age }>55 \text { years for females or premature } \\
\text { menopause }\end{array}$ & $0(0 \%)$ & $0(0 \%)$ & - \\
\hline $\begin{array}{l}\text { Hypertension }(>140 \mathrm{mmHg} \text { for systolic } \\
>90 \mathrm{mmHg} \text { for diastolic) }\end{array}$ & $0(0 \%)$ & $0(0 \%)$ & - \\
\hline $\begin{array}{l}\text { Impaired fasting glucose } \\
\quad \text { (Glucose }<126 \text { and }>110 \mathrm{mg} / \mathrm{dl})\end{array}$ & $0(0 \%)$ & $8(12 \%)$ & 0.01 \\
\hline Diabetes mellitus (Glucose $>126 \mathrm{mg} / \mathrm{dl}$ ) & $0(0 \%)$ & $5(7 \%)$ & 0.04 \\
\hline Obesity $\left(\mathrm{BMI}>30 \mathrm{~kg} / \mathrm{m}^{2}\right)$ & $2(4 \%)$ & $7(10 \%)$ & 0.19 \\
\hline Smoking & $22(42 \%)$ & $37(54 \%)$ & 0.21 \\
\hline Hyperuricemia $(>7.5 \mathrm{mg} / \mathrm{dl})$ & $0(0 \%)$ & $12(17 \%)$ & 0.001 \\
\hline High total cholesterol $(>200 \mathrm{mg} / \mathrm{dl})$ & $0(0 \%)$ & $22(32 \%)$ & $<0.001$ \\
\hline Low HDL cholesterol $(<35 \mathrm{mg} / \mathrm{dl})$ & $13(25 \%)$ & $36(52 \%)$ & 0.002 \\
\hline High LDL cholesterol (>130 mg/dl) & $0(0 \%)$ & $28(41 \%)$ & $<0.001$ \\
\hline High trigylceride $(>200 \mathrm{mg} / \mathrm{dl})$ & $1(2 \%)$ & $7(10 \%)$ & 0.07 \\
\hline Total cholesterol/HDL $(>4.5)$ & $17(32 \%)$ & $55(80 \%)$ & $<0.001$ \\
\hline LDL/HDL $(>30)$ & $10(19 \%)$ & $56(81 \%)$ & $<0.001$ \\
\hline Positive family history* & $8(15 \%)$ & $0(0 \%)$ & $<0.001$ \\
\hline
\end{tabular}

*Myocardial infarction or sudden death in first degree consanguity in men before 55, in women before 65 years of age

In the literature on CHD risk factors in SCI, the patient populations have different age, time since injury, and different risk factors inherent from their population of origin. The results from these studies are difficult to compare if the population of origin is not taken into account. Therefore we analyzed our results first by comparing them with our controls, then with two big Turkish population studies, and finally with the SCI population elsewhere.

TC and LDL levels were significantly increased in $32 \%$ and $41 \%$ of the SCI patients compared to controls. In the 1990 results of the prospective TEKHARF study on CHD risk factors in Turkey,
$25 \%$ of the cohort had $\mathrm{TC}>200 \mathrm{mg} / \mathrm{dl}^{22}$ In the Turkish Heart Study Mahley have reported similar prevalence rates; for high TC $32 \%$ in men, $22 \%$ in women, and for high LDL (>130 mg/dl) $37 \%$ in men, $28 \%$ in women, respectively. ${ }^{23}$ These results indicate that the study controls were clearly different from the representative Turkish populations of the TEKHARF and the Turkish Heart Study cohort. However, while the study controls were chosen from young and healthy population, these cohorts included healthy and diseased people randomly sampled from Turkey which explains the difference. The increased lipid levels seen in SCI patients may be due to the influence of enforced 
sedentary lifestyle of our SCI patients acting over the standard factors of diet and level of physical activity in the Turkish population. TC and LDL levels of our SCI patients seemed higher than seen in other studies (Maki with $26 \%, 33 \%$, Tharion with $8 \%, 10 \%)^{8,24}$ with exception of nearly similar values of LDL $(44 \%)$ reported in the study of Bauman. ${ }^{7}$ This observed difference may be due to longer time since injury in the aforementioned studies which may select surviving patients with good lipoprotein profile and differences in basic risk factors of their parent population.

HDL levels were significantly depressed in $52 \%$ of our SCI patients compared to controls $(25 \%)$. HDL showed inverse correlations with the time since injury, TG, TC/HDL, and LDL/HDL ratios. High TG levels described as level $>200 \mathrm{mg} / \mathrm{dl}$ were present in $10 \%$ of the SCI patients and in $2 \%$ of the controls. In the Turkish Heart Study $53 \%$ of Turkish men and $26 \%$ of Turkish women had HDL levels $<35 \mathrm{mg} / \mathrm{dl} .{ }^{23}$ The same prevalences were $15 \%$, and $5 \%$ for American men and women, respectively. The difference may be genetically determined; probably due to increase of hepatic lipase activity in the Turkish population. In the TEKHARF study high TG was found in $15 \%$ of males, and in $10 \%$ of females which were comparable to our SCI patients. ${ }^{22}$ The prevalence of low HDL $(<35 \mathrm{mg} / \mathrm{dl}, 52 \%)$ and high TG $(>150 \mathrm{mg} / \mathrm{dl}, 26 \%)$ in our SCI patients were comparable to prevalence reported by Tharion et al $(58 \%$ and $21 \%)$ and Maki et al $(41 \%$ and $32 \%) .{ }^{8,24}$ However, the ratios TC/HDL and LDL/HDL, a stronger predictor of CHD risk ${ }^{25}$ were numerically and percentagewise higher than observed in other studies $(5.73 \pm 1.39,3.82 \pm 1.11$ vs Baumann with $5.1 \pm 0.1$; $80 \%, 81 \%$ vs Maki with $57 \%, 56 \%$ ) in SCI. ${ }^{7,8}$ They were also higher than controls (32\% and $19 \%)$, and in those observed in the Turkish Heart Study cohort (TC/ HDL $>4.5$ in $64 \%$ of men, in $38 \%$ of women). ${ }^{23}$ Maki et al and other authors have suggested that the high prevalence of these ratios in their SCI patients was primarily due to a high prevalence of reduced HDL. But the higher ratios seen in our study may be due to other factors that may influence HDL levels, like smoking, genetic factors mentioned above, and lower levels of physical activity. This may be ascertained by the finding of increased adverse risk profile for CHD in our SCI patients with time since injury more than 12 months and the negative correlation of HDL with time since injury. We found no relation of low HDL levels with other putative factors like level of injury, completeness of lesion, obesity, alcohol consumption, and medications like beta blockers, diuretics etc. The lack of the association between HDL and level or completeness of lesion may be due to the relatively small sample size of our study group.

Our SCI patients had a significantly increased DM $(7 \%)$, and IFG $(12 \%)$ prevalence compared to controls. The calculated prevalence of DM was $6.3 \%$ for females, and $4.6 \%$ for males in the TEKHARF cohort in 1990, comparable to our SCI patient group. ${ }^{26}$ In the TEKHARF study subjects were diagnosed as diabetic if their fasting plasma glucose (FPG) were $>130 \mathrm{mg} / \mathrm{dl}$ or if they gave a history of diabetes. Slightly fewer people will be diagnosed with diabetes if the new FPG criteria is used alone than if either the FPG or the oral glucose tolerance test (OGTT) is used and interpreted by the previous World Health Organization (WHO) and National Diabetes Data Group (NDDG) criteria. ${ }^{20,27,28}$ Although the OGTT and FPG are both suitable tests, in epidemiological studies, the FPG is strongly recommended because it is easier and faster to perform, more convenient and acceptable to patients and controls, more reproducible, and less expensive. Tharion $e t a l^{24}$ and Duckworth et $a l^{29}$ have reported higher prevalence of DM and impaired glucose tolerance $(19 \%$ and $23 \% ; 23 \%$ and $40 \%$, respectively), may be due to different cutpoint values or to different methodology used. Our SCI patients had a prevalence of $10 \%$, our controls of $4 \%$ for obesity. The prevalence of obesity described as BMI $>30 \mathrm{~kg}$ / $\mathrm{m}^{2}$ was present in $9 \%$ of males and in $28.5 \%$ of females in the TEKHARF cohort in $1990,{ }^{30}$ comparable to Western males, and our SCI patients which were mostly males. In other SCI studies ${ }^{5,8}$ BMI were in the range of 25.5-26.0 comparable to our SCI patients and to the TEKHARF cohort for men (25.4 for men, 27.7 for women). The differences between our SCI patients and other SCI populations may be due to shorter duration since injury and younger age of our SCI patients. Our SCI patients had a significantly increased hyperuricemia prevalence $(17 \%)$ compared to controls. SUA levels were correlated with $\mathrm{TC}$, TG, and $\mathrm{TC} / \mathrm{HDL}$ ratio which may imply that our SCI patients have some features of the metabolic syndrome (also known as syndrome $\mathrm{X}$ or the insulin resistance syndrome) and thus are at increased risk for CHD. ${ }^{31}$ However, prevalences of obesity, HT, and IFG of our SCI patients were not high. In addition, whatever the cause, increased SUA levels were accepted as an independent cardiovascular risk factor. ${ }^{32,33}$ The results of these two studies both demonstrated that a single, baseline SUA predicted cardiovascular disease mortality over the ensuing 20 years.

We concluded, that compared to other SCI populations, our SCI patients were younger, smoked more, had higher TC, LDL levels, and TC/HDL, $\mathrm{LDL} / \mathrm{HDL}$ ratios, but lower prevalence of HT and DM. SCI seems to confer additional CHD risk factors due to sedentary lifestyle over the preexisting risk profile of the parent population which increases with time since injury. 


\section{References}

1 Yekutiel M et al. The prevalence of hypertension, ischaemic heart diseases and diabetes in traumatic spinal cord injured patients and amputees. Paraplegia 1989; 27: 58-62.

2 Whiteneck GG et al. Mortality, morbidity, and psychosocial outcomes of persons spinal cord injured more than 20 years ago. Paraplegia 1992; 30: 617-630.

3 DeVivo MJ, Black KJ, Stover SL. Causes of death during the first 12 years after spinal cord injury. Arch Phys Med Rehabil 1993; 74: $248-254$.

4 Brenes $\mathrm{G}$ et al. High density lipoprotein cholesterol concentrations in physically active and sedentary spinal cord injured patients. Arch Phys Med Rehabil 1986; 67: 445-450.

5 Dearwater SR et al. Activity in the spinal cord injured patient: an epidemiologic analysis of metabolic parameters. Med Sci Sports Exerc 1986; 18: $541-544$.

$6 \mathrm{Krum} \mathrm{H}$ et al. Risk factors for cardiovascular disease in chronic spinal cord injury patients. Paraplegia 1992; 30: $381-388$.

7 Bauman WA et al. Depressed serum high density lipoprotein levels in veterans with spinal cord injury. Paraplegia 1992; 30: $697-703$.

8 Maki KC et al. Associations between serum lipids and indicators of adiposity in men with spinal cord injury. Paraplegia 1995; 33: $102-109$.

9 Kocina P. Body composition of spinal cord injured adults. Sports Med 1997; 23: 48 - 60.

10 Bauman WA et al. The effect of residual neurologic deficit on serum lipoproteins in individuals with spinal cord injury. Spinal Cord 1998; 36: $13-17$

11 Dallmeijer AJ, Hopman MTE, van der Woude LHV. Lipid, lipoprotein and apolipoprotein profiles in active and sedentary men with tetraplegia. Arch Phys Med Rehabil 1997; 73: $1173-$ 1176.

12 Walker J, Shephard RJ. Cardiac risk factors immediately following spinal injury. Arch Phys Med Rehabil 1993; 74: $1129-1133$

13 Dallmeijer AJ, van der Woude LHV, van Kamp GJ, Hollander AP. Changes in lipid, lipoprotein and apolipoprotein profiles in persons with spinal cord injuries during the first 2 years postinjury. Spinal cord 1999; 37: 96-102.

14 Bauman WA, Spungen AM. Disorders of carbohydrate and lipid metabolism in veterans with paraplegia or quadriplegia: A model of premature aging. Metabolism 1994; 43: 749-756.

15 Expert Panel on Detection, Evaluation, and Treatment of High Blood Cholesterol in Adults National Cholesterol Education Program. Second report of the Expert Panel on Detection, Evaluation and Treatment of High Blood Cholesterol in Adults (Adult Treatment Panel II). Circulation 1994; 89: 1329-1445.

16 Maynard FM et al. International Standards for Neurological and Functional Classification of Spinal Cord Injury. Spinal Cord 1997; 35: 266-274.

17 Hubert HB, Feinleib M, Mcnamara PM, Castelli WP. Obesity as an independent risk factor for cardiovascular disease: a 26-year follow-up of participants in the Framingam Heart Study. Circulation 1983; 67: $968-977$.
18 Valdez R, Siedell JC, Ahn YI, Weiss KM. A new index of abdominal adiposity as an indicator of risk for cardiovascular disease: a cross-population study. Int J Obesity 1992; 17: 77 -82.

19 Joint National Committee on Prevention, Detection, Evaluation, and Treatment of High Blood Pressure. The Sixth Report of the Joint National Committee on Prevention, Detection, Evaluation, and Treatment of High Blood Pressure (JNC VI). Arch Intern Med 1997; 157: 2413-2446.

20 The Expert Committee on the Diagnosis and Classification of Diabetes Mellitus. Report of the Expert Committee on the Diagnosis and Classification of Diabetes Mellitus. Diabetes Care 1998; 21 (Suppl I): S5 - S19.

21 Friedewald WT, Levy RI, Fredrickson DS. Estimation of the concentration of low-density lipoprotein cholesterol in plasma without the use of a preparative ultracentrifuge. Clin Chem 1972; 18: $499-502$.

22 Tokgözoğlu LS. Türklerde Kolesterol ve Trigliserid Değerleri. In: Onat A (eds). TEKHARF Türk Erişkinlerinde Kalp Sağlığının Dünü ve Bugünü: TEKHARF ÇCalışmasinın Sağladiğ Ü,c Boyutlu Harita. 1st edn. Karakter Color Matbaasi: İstanbul, 1996, pp $43-59$.

23 Mahley RW et al. Turkish Heart Study: lipids, lipoproteins, and apoliporoteins. J Lipid Res 1995; 36: 839-861.

24 Tharion G, Prasad RK, Gopalan L, Bhattacharji S. Glucose intolerance and dyslipidemias in persons with paraplegia and tetraplegia in South India. Spinal Cord 1998; 36: 228-230.

25 Stampfer MJ et al. A prospective study of cholesterol, apolipoproteins, and the risk of myocardial infarction. $N$ Engl J Med 1991; 325: 373 - 381.

26 Onat A. Türk Erişkinlerinde Glukoz İntoleransi ve Diyabet. In: Onat A (eds). TEKHARF Türk Eriskinlerinde Kalp Sağlı̌̆inin Dünü ve Bugünü: TEKHARF Çalışmasinin Sağladigii Üç Boyutlu Harita. 1st edn. Karakter Color Matbaasi: İstanbul 1996, $101-$ 111.

27 National Diabetes Data Group. Classification and diagnosis of diabetes mellitus and other categories of glucose intolerance. Diabetes 1979; 28: 1039 - 1057.

28 World Health Organization. Diabetes Mellitus: Report of a WHO Study Group. Geneva, World Health Org., 1985 (Tech. Rep. Ser., no. 727).

29 Duckworth WC, Jallepalli P, Solmon SS. Glucose Intolerance in Spinal Cord Injury. Arch Phys Med Rehabil 1983; 64: 107-110.

30 Sansoy V. Türk Erişkinlerinde Beden Kitle Endeksi ve Bel Kalça Oranlari. In: Onat A (eds). TEKHARF Türk Erişkinlerinde Kalp Sağlı̆̆inin Dünü ve Bugünü: TEKHARF Çalışmasinin Sağladigi $\ddot{U}$ c Boyutlu Harita. 1st edn. Karakter Color Matbassı: İstanbul 1996, pp 89-100.

31 Reaven GM. Role of insulin resistance in human disease. Diabetes 1988; 37: 1595-1607.

32 Levine et al. Serum uric acid and 11.5-year mortality of middleaged women: Findings of the Chicago Heart Association Detection Project in Industry. J Clin Epidemiol 1989; 42: $257-$ 267.

33 Freedman DS et al. Relation of serum uric acid to mortality and ischemic heart disease. Am J Epidemiol 1995; 141: 637-644. 